УдК 615.322:615.074

\title{
СРАВНИТЕЛЬНОЕ ИЗУЧЕНИЕ СОДЕРЖАНИЯ ФЛАВОНОИДОВ И КУМАРИНОВ В НЕКОТОРЫХ ПРЕПАРАТАХ РОМАШКИ АПТЕЧНОЙ
}

\author{
(C) В.М. Косман ${ }^{*}$ О.Н. Пожарицкая, А.Н. Шиков, В.Г. Макаров
}

\author{
Санкт-Петербургский институт фрармации, г.п. Кузьмоловское, корп. 245, \\ Всеволожский район, Ленинградская область (Россия), \\ e-mail:spbpharm@mail.ru
}

\begin{abstract}
Цветки ромашки аптечной Chamomilla recutita (L.) Rauschert используют в медицине в качестве противовоспалительного, спазмолитического и слабого антисептического средства. Основные виды фармакологической активности - спазмолитическое и противовоспалительное действия - цветков ромашки обусловлены присутствием в них флавоноидов и кумаринов. Расширение ассортимента лекарственных препаратов на основе цветков ромашки возможно за счет использования гидрофобных экстрагентов, например растительных масел.

Методами УФ-спектроскопии и высокоэффективной жидкостной хроматографии с УФ-детектированием сопоставлен состав флавоноидов и кумаринов масляного экстракта цветков ромашки, полученного по оригинальной технологии, официнальных настоя и настойки (40\% этанол).

Выполнен сравнительный анализ состава и содержания флавоноидов и кумаринов в масляном экстракте цветков ромашки аптечной (МЭР), полученном по оригинальной технологии, официнальных настое и настойке (40\% этанол). Во всех исследованных препаратах обнаружены умбеллиферон, герниарин и апигенин, а также два гидрофобных соединения, относящиеся к классу ен-ин-дициклоэфиров.

Установлено, что содержание флавоноидов в МЭР значительно ниже, чем в препаратах сравнения, из-за низкой растворимости флавоноидных гликозидов и кверцетина в растительном масле. Показано, что по суммарному содержанию кумаринов масляный экстракт ромашки превосходит настой и настойку ромашки.

Оценены общие закономерности экстракции флавоноидов и кумаринов цветков ромашки аптечной экстрагентами различной полярности (воды, $40 \%$ спирта и соевого масла) и показано, что флавоноиды лучше переходят в спиртовое извлечение, а более гидрофобные компоненты (кумарины, ен-ин-дициклоэфиры) лучше экстрагируются растительным маслом.

Ключевые слова: ромашка аптечная, флавоноиды, кумарины, масляный экстракт цветков.

Работа выполнена при финансовой поддержке государства в лище Минобрнауки России (Соглашение №14.576.21.0010 от 17.06.2014. Уникальный идентификатор прикладных научных исследований RFMEFI57614X0010).
\end{abstract}

\section{Введение}

В традиционной медицине различных стран мира применяют препараты из цветков ромашки аптечной

Косман Вера Михайловна - руководитель группы химико-аналитических исследований, старший научный сотрудник, кандидат фармацевтических наук, e-mail:kosmanvm@mail.ru, spbpharm@mail.ru Пожариикая Ольга Николаевна - руководитель отдела новых технологий и стандартизации, заместитель генерального директора, ведущий научный сотрудник, кандидат фармацевтических наук,

e-mail: olgapozhar@mail.ru

Шиков Александр Николаевич - заместитель генерального директора, ведущий научный сотрудник, доктор фармацевтических наук, e-mail: alexs79@mail.ru Макаров Валерий Геннадиевич - профессор, доктор медицинских наук, e-mail: spbpharm@mail.ru
(Matricaria recutita (L.) Rauschert, син. Matricaria chamomilla L.) в качестве противовоспалительных, спазмолитических и умеренно-выраженных антисептических средств. Среди показаний к их назначению для приема внутрь ведущее место занимают гастриты, язвенная болезнь желудка и 12-перстной кишки [1-3].

В настоящее время наиболее полно изучены эфирное масло и фенольные соединения ромашки. В различных органах ромашки аптечной обнаружено более 30 флавоноидов, включая апигенин, кверцетин, изорамнетин, 7-глюкозид лютеолина, 7-глюкозид

\footnotetext{
* Автор, с которым следует вести переписку.
} 
апигенина и хризоэриол. При этом их суммарное содержание достигает 1,2\% [4]. Среди биологически активных липофильных соединений ромашки аптечной важными являются $\alpha$-бисаболол и полиины, такие как иис-ен-ин-бициклоэфиры (спироэфиры) [5]. Из соцветий ромашки аптечной выделена группа высокометилированных флавоноидов, называемых «липофильными флавоноидами», оксикумарины (умбеллифенон и его метиловый эфир - герниарин) [6].

Противовоспалительное действие экстрактов ромашки, по имеющимся литературным сведениям, обусловлено веществами, входящими в состав эфирного масла, а также иис- и транс-спироэфирами [6]. Для флавоноида апигенина установлены спазмолитическое, противовоспалительное и седативное действия $[4,7]$. Оксикумарины умбеллиферон (содержание достигает $0,016 \%$ ) и его метиловый эфир герниарин (содержание до 0,039\%), обнаруженные в цветках ромашки, также обладают спазмолитической активностью [6].

Цветки ромашки являются официнальным лекарственным растительным сырьём, их применяют в качестве противовоспалительного и спазмолитического средства в виде настоя [8]. Кроме того, промышленно выпускаются препараты Ромазулан, содержащий экстракт ромашки жидкий и азулен с добавлением в качестве эмульгатора твина-80, и Ротокан, содержащий смесь жидких экстрактов ромашки, тысячелистника и календулы (в соотношении $2: 1: 1$ ) [1]. Возможности создания новых препаратов на основе ромашки аптечной далеко не исчерпаны. Прежде всего это касается использования гидрофобных экстрагентов для получения липофильных комплексов ромашки аптечной, в которых наблюдается иное соотношение гидрофильных и гидрофобных биологически активных соединений. В качестве гидрофобных экстрагентов могут быть использованы различные растительные масла [9].

Масляный экстракт цветков ромашки аптечной (МЭР) является перспективным объектом для создания новых препаратов и продуктов на его основе. Для разработки и стандартизации таких препаратов необходимо оценить качественный и количественный состав биологически активных веществ МЭР, а также сопоставить его с аналогичными характеристиками уже известных и применяемых препаратов. Кроме стандартизации, сопоставление таких данных может быть важно для первоначальной оценки дозировки МЭР в доклинических исследованиях.

Основной целью настоящей работы являлось изучение влияния условий извлечения на выход и состав биологически активных соединений цветков ромашки аптечной.

\section{Материалы и методы}

В работе использовали коммерчески доступные цветки ромашки аптечной (Flores Chamomillae), coответствующие требованиям [10]. Масляный экстракт ромашки получали по оригинальной технологии роторно-пульсационной экстракции [9] при соотношении сырье : экстрагент $1: 10$ с использованием в качестве экстрагента кукурузного масла (ГОСТ 8808-2000). Настойку получали методом перколяции $40 \%$ спиртом в соотношении $1: 10$. Настой ромашки получали в соответствии с требованиями Государственной фармакопеи X1.

Для анализа индивидуальных флавоноидов и кумаринов применяли метод обращенно-фазной высокоэффективной жидкостной хроматографии с использованием жидкостного хроматографа LC-20 Prominence (Shimadzu, Япония) с диодно-матричным детектором и колонкой Luna C18 (2) (4,6×150 мм, 5 нм) и предколонкой (3,0 мм), заполненной тем же сорбентом (Phenomenex, США), в режиме ступенчатого элюирования смесью ацетонитрил - 0,03\% водный раствор трифторуксусной кислоты, включающем изократический (15\% ацетонитрила в течение 5 мин) и градиентный участки (с линейным изменением концентрации ацетонитрила от 15 до $100 \%$ в течение 40 мин). Скорость потока элюента 1,0 мл/мин. Обработку хроматограмм проводили с помощью программного обеспечения LCSolution (Shimadzu, Япония).

Идентификацию основных индивидуальных компонентов в исследованных образцах экстрактов кумаринов (умбеллиферон, герниарин) и флавоноидов апигенина и кверцетина производили с использованием веществ-свидетелей.

В изучаемых образцах оценивали следующие группы биологически активных веществ (БАВ):

- Определение суммарного содержания флавоноидов в пересчете на кверцетин проводили методом дифференциальной спектрофотомерии по образованию окрашенных продуктов реакции с хлоридом алюминия (III) при длине волны 430 нм. Подготовка проб МЭР включала экстракцию флавоноидов этанолом с последующей обработкой проб гексаном для устранения компонентов растительного масла, мешающих дальнейшему анализу [11]. 
- Определение суммарного содержания кумаринов в пересчете на кумарин проводили методом прямой спектрофотометрии при длине волны 310 нм с использованием значения удельного показателя поглощения кумарина $E_{1 c m}^{1 \%}=356$. Подготовка проб включала обработку образцов раствором ацетата свинца для осаждения флавоноидов и других гидрофильных фенольных соединений, экстракцию кумаринов хлороформом с последующей заменой растворителя на спирт этиловый. Образцы МЭР предварительно обрабатывали этанолом для экстракции фенольных соединений и флавоноидов из гидрофобной матрицы.

В качестве стандартных образцов использовали образцы кумарина, умбеллиферона, герниарина, апигенина и кверцетина (Sigma-Aldrich, Fluka, Германия).

Данные представлены в виде среднего M \pm относительное стандартное отклонение SEM в мг/кг.

Статистическая обработка данных выполнена с помощью программного обеспечения Microsoft Office Excel 2007.

\section{Результаты и обсуждения}

Выход биологически активных веществ при экстрагировании в наибольшей степени зависит от природы растворителя. Результаты количественного определения суммарного содержания флавоноидов и кумаринов, а также содержания некоторых индивидуальных соединений этих групп в препаратах ромашки представлены в таблицах 1 и 2.

Идентификация основных компонентов в исследованных образцах - кумаринов умбеллиферона, герниарина и флавоноидов апигенина и кверцетина - выполнена с применением стандартных образцов определяемых соединений по совпадению хроматографических (времена удерживания, индексы удерживания $[12,13])$ и спектральных (спектральные отношения $[12,13]$, диодно-матричные спектры) характеристик. Кроме четырех перечисленных соединений, на хроматограммах растворов всех исследуемых образцов были зарегистрированы значимые пики двух неизвестных соединений. Методом ГХ-МС они были идентифицированы как ен-ин-дициклоэфиры: (E)-2-[2,4-гексадиинилиден]-1,6-диоксаспиро[4,4]-нон-3-ен (1) и (Z)- 2-[2,4-гексадиинилиден]-1,6-диоксаспиро[4,4]-нон-3-ен (2) [14]. Диодно-матричные спектры двух рассматриваемых соединений идентичны и близки к спектру кумарина (для них характерны максимумы поглощения около 258 нм и 319 нм), что позволяет проводить оценку их содержания в пересчете на кумарин при отсутствии стандартных образцов.

Из данных, представленных в таблице 1, следует, что по суммарному содержанию кумаринов МЭР превосходит настой и настойку цветков ромашки. Установлено (табл. 2), что содержание наиболее гидрофобного ен-ин-дициклоэфира 2 в МЭР значительно выше его содержания в других исследованных образцах.

Суммарное содержание флавоноидов в МЭР значительно ниже, чем в препаратах сравнения. Это согласуется с данными по содержанию индивидуальных флавоноидов в исследованных препаратах (табл. 2). В МЭР удалось идентифицировать и количественно определить только один флавоноид - апигенин. В структуре апигенина имеются три гидроксильные группы, в отличие от кверцетина, в структуре которого пять гидроксильных групп. Соответственно, растворимость апигенина в гидрофобном (липофильном) растворителе несколько выше, чем у кверцетина. За счет низкой растворимости в масле кверцетин и другие флавоноидные гликозиды отсутствуют в МЭР.

Результаты количественного содержания флавоноидов, полученные методами ВЭЖХ и дифференциальной спектрофотометрии с алюминия хлоридом, значительно различаются. Вероятно, это связано с тем, что методом ВЭЖХ идентифицированы и количественно определены не все индивидуальные флавоноиды, содержащиеся в препаратах.

На основании сопоставления данных по содержанию кумариновых соединений, полученных методами ВЭЖХ и спектрофотометрии в исследованных образцах (табл. 3), показано удовлетворительное совпадение результатов двух различных методов.

Таблица 1. Суммарное содержание кумаринов и флавоноидов в препаратах ромашки аптечной (мг/кг, M \pm SEM)

\begin{tabular}{l|c|c}
\hline \multicolumn{1}{c|}{ Показатель } & МЭР & Настой \\
\hline Суммарное содержание флавоноидов в пересчете на кверцетин & $45,0 \pm 1,2$ & $170,0 \pm 2,0$ \\
Суммарное содержание кумаринов в пересчете на кумарин & $540,0 \pm 14,3$ & $70,0 \pm 2,4$ \\
\hline
\end{tabular}


Таблица 2. Содержание некоторых индивидуальных кумаринов и флавоноидов в препаратах ромашки аптечной (мг/кг, $\mathrm{M} \pm \mathrm{SEM})$

\begin{tabular}{l|c|c|c}
\hline \multicolumn{1}{c|}{ Соединение } & МЭР & Настой & Настойка \\
\hline Умбеллиферон & $12,5 \pm 0,4$ & $13,4 \pm 0,2$ & $17,5 \pm 0,7$ \\
Герниарин & $48,6 \pm 1,2$ & $11,0 \pm 0,2$ & $50,0 \pm 2,0$ \\
Ен-ин-дициклоэфир 1 & $76,4 \pm 2,6$ & $4,9 \pm 0,2$ & $43,0 \pm 1,3$ \\
Ен-ин-дициклоэфир 2 & $388,0 \pm 7,0$ & $6,7 \pm 0,3$ & $72,0 \pm 1,5$ \\
Апигенин & $4,1 \pm 0,2$ & $3,3 \pm 0,1$ & $36,0 \pm 1,7$ \\
Кверцетин & Не детектируется & $32,0 \pm 1,4$ & $70,6 \pm 3,2$ \\
\hline
\end{tabular}

Таблица 3. Сравнение результатов количественного определения кумаринов, полученных методами ВЭЖХ и спектрофотометрии в препаратах ромашки (мг/кг, $\mathrm{M} \pm \mathrm{SEM})$

\begin{tabular}{|c|c|c|c|}
\hline Метод & МЭР & Настой & Настойка \\
\hline $\begin{array}{l}\text { Спектрофотометрия: } \\
\text { суммарное содержание кумаринов в пересчете на кумарин } \\
\text { ВЭЖХ метод: } \\
\text { суммарное содержание четырех индивидуальных соединений }\end{array}$ & $\begin{array}{l}540 \pm 14 \\
525 \pm 15\end{array}$ & $\begin{array}{l}70 \pm 2 \\
36 \pm 1\end{array}$ & $150 \pm 5$ \\
\hline
\end{tabular}

На основании данных о количественном содержании исследуемых компонентов в образцах настоя, настойки и МЭР, полученных из сырья одной партии, можно проследить некоторые общие закономерности экстракции флавоноидов и кумаринов цветков ромашки аптечной экстрагентами различной полярности (вода, $40 \%$ этиловый спирт и растительное масло). Так, наиболее обогащенным флавоноидами, как по их суммарной оценке, так и по содержанию индивидуальных соединений, в этом ряду является извлечение с использованием 40 \% этанола (настойка). Максимальное суммарное содержание кумаринов достигнуто при экстракции сырья кукурузным маслом. Однако индивидуальные соединения экстрагируются из сырья не одинаково (табл. 1). Так, гидрофильный умбеллиферон примерно в одинаковых концентрациях присутствует во всех трех извлечениях, герниарин - преобладает в настойке и МЭР, а гидрофобные ен-индициклоэфиры 1 и 2 переходят в кукурузное масло в существенно бо́льших количествах, чем в воду или $40 \%$ этанол. Таким образом, масляный экстракт ромашки является перспективным для создания новых препаратов и продуктов на его основе.

\section{Заключение}

Во всех исследованных препаратах цветков ромашки аптечной обнаружены умбеллиферон, герниарин и апигенин, а также два гидрофобных соединения, относящиеся к классу ен-ин-дициклоэфиров.

Установлено, что содержание флавоноидов в МЭР значительно ниже, чем в препаратах сравнения, из-за низкой растворимости флавоноидных гликозидов и кверцетина в растительном масле. Показано, что по суммарному содержанию кумаринов масляный экстракт ромашки превосходит настой и настойку ромашки за счет значительного содержания гидрофобных соединений кумариновой природы.

Показано, что при получении извлечений из цветков ромашки с применением в качестве экстрагентов воды, $40 \%$ спирта и кукурузного масла, наибольшее содержание флавоноидов достигнуто при экстракции $40 \%$ этанолом, а наиболее обогащенный гидрофобными кумаринами и ен-ин-дициклоэфирами продукт получен при использовании экстрагента растительного масла.

\section{Список литературь}

1. Машковский М.Д. Лекарственные средства. 16-е изд., перераб. и доп. М., 2012. 1216 с.

2. Gupta V., Mittal P., Bansal P., Khokra S.L., Kaushik D. Pharmacological Potential of Matricaria recutita. A Review // Int. J. Pharm. Sci. Drug Research. 2010. Vol. 2, N1. Pp. 12-16.

3. Shikov A.N., Pozharitskaya O.N., Makarov V.G., Kvetnaya A.S. Antibacterial activity of Chamomilla recutita oil extract against Helicobacter pylori // Phytother. Res. 2008. Vol. 22, N2. Pp. 252-253.

4. Haghi G., Hatami A., Safaeil A., Mehran M. Analysis of phenolic compounds in Matricaria chamomilla and its extracts by UPLC-UV // Research in Pharmaceutical Sciences. 2014. Vol. 9, N1. Pp. 31-37.

5. Ompal S., Zakia K., Neelam M., Manoj K.S. Chamomile (Matricaria chamomilla L.): An overview // Pharmacogn. Rev. 2011. Vol. 5, N9. Pp. 82-95. 
6. McKay D.L., Blumberg J.B. A Review of the Bioactivity and Potential Health Benefits of Chamomile Tea (Matricaria recutita L.). // Phytother. Res. 2006. Vol. 20. Pp. 519-530.

7. Avallone R., Zanoli P., Puia G., Kleinschnitz M., Schreier P., Baraldi M. Pharmacological profile of apigenin, a flavonoid isolated from Matricaria chamomilla // Biochem Pharmacol. 2000. Vol. 59, N11. Pp. 1387-1394.

8. Shikov A.N., Pozharitskaya O.N., Makarov V.G., Wagner H., Verpoorte R., Heinrich M. Medicinal plants of the Russian Pharmacopoeia; their history and applications. // J. Ethnopharmacol. 2014. Vol. 154, N3. Pp. 481-536.

9. Шиков А.Н., Макаров В.Г., Рыженков В.Е. Растительные масла и масляные экстракты: технология, стандартизация, свойства. М., 2004. 264 с.

10. Государственная Фармакопея СССР, изд. 11-е перераб. и доп., М., 1987, Вып. 1. 335 с.; 1989, Вып. 2. 398 с.

11. Пименов А.И., Станкевич Н.М., Макаров В.Г., Зенкевич И.Г. Спектрофотометрический метод количественного определения флавоноидов в масляных экстрактах (на примере масляного экстракта листьев крапивы) // Актуальные проблемы создания новых лекарственных препаратов природного происхождения: материалы $\mathrm{V}$ междун. съезда. СПб., 2001. С. 354-356.

12. Косман В.М., Зенкевич И.Г. Информационное обеспечение для идентификации фенольных соединений растительного происхождения в обращенно-фазовой ВЭЖХ. Флавоны, флавонолы, флаваноны и их гликозиды // Растительные ресурсы. 1997. Т. 33, вып. 2. С. 14-26.

13. Косман В.М., Зенкевич И.Г., Комиссаренко Н.Ф. Информационное обеспечение для идентификации фенольных соединений растительного происхождения в обращенно-фазовой ВЭЖХ. Природные кумарины и фурокумарины // Растительные ресурсы. 1997. Т. 33, вып. 3. С. 32-37.

14. Shikov A.N., Laakso I., Pozharitskaya O.N., Dorman D., Makarov V.G., Tikhonov V.P., Hiltunen R. Identification of spiroketal polyacetylenes as the main components of an oil extract of chamomile (Chamomilla recutita L. Rausch.) flowers // Planta Medica. 2006. Vol.72, N11. Pp. 1026.

Поступило в редакичию 24 июля 2014 г.

После переработки 9 октября 2014 г. 
Kosman V.M. , Pozharitskaia O.N., Shikov A.N., Makarov V.G. COMPARATIVE STUDY OF FLAVONOIDS AND COUMARINS IN MEDICINAL PREPARATIONS OF CHAMOMILLA RECUTITA (L.) RAUSCHERT

St. Petersburg Institute of Pharmacy, Kuzmolovsky, 245, Vsevolozhsk district, Leningrad region (Russia), e-mail: spbpharm@mail.ru

Flowers of Chamomilla recutita (L.) Rauschert are used in medicine as anti-inflammatory, spasmolytic and antiseptic drug. Main pharmacological effects are associated with flavonoids and coumarins. Development of new preparations from Chamomilla is possible on the base of lypophylic extra gents application such as plant oils..

Flavonoids and coumarins composition of oil extract of Chamomilla flowers, infusion and tincture was analyzed by UV-spectroscopy and UV-HPLC. Umbelliferone, herniarin, apigenin and quercetin were founded in all preparations, while quercetin was not found in oil extract only. Two hydrophobic compounds identified as en-yn-dicycloethers also were determined in all preparations.

It was established that total flavonoids content in oil extract is less than in other preparations because of low solubility of flavonoid glycosides and aglycones in plant oil. Total coumarins quantity in oil extract is higher than in Rotokan, water extract and tincture and less only than in Romazulan.

It was established that ethanol was the most suitable extragent for flavonoids while more hydrophobic compound (coumarins and en-yn-dicycloethers) were abundant in oil extract.

Keywords: Chamomilla recutita, flavonoids, coumarins, flowers oil extract

\section{References}

1. Mashkovskii M.D. Lekarstvennye sredstva. [Drugs]. 16 ed. Moscow, 2012, 1216 p. (in Russ.).

2. Gupta V., Mittal P., Bansal P., Khokra S.L., Kaushik D. Int. J. Pharm. Sci. Drug Research, 2010, vol. 2, no. 1, pp. 12-16.

3. Shikov A.N., Pozharitskaya O.N., Makarov V.G., Kvetnaya A.S. Phytother. Res., 2008, vol. 22, no. 2, pp. $252-253$.

4. Haghi G., Hatami A., Safaeil A., Mehran M. Research in Pharmaceutical Sciences, 2014, vol. 9, no. 1, pp. 31-37.

5. Ompal S., Zakia K., Neelam M., Manoj K.S. Pharmacogn. Rev., 2011, vol. 5, no. 9, pp. 82-95.

6. McKay D.L., Blumberg J.B. Phytother. Res., 2006, vol. 20, pp. 519-530.

7. Avallone R., Zanoli P., Puia G., Kleinschnitz M., Schreier P., Baraldi M. Biochem Pharmacol., 2000, vol. 59, no. 11, pp. 1387-1394.

8. Shikov A.N., Pozharitskaya O.N., Makarov V.G., Wagner H., Verpoorte R., Heinrich M. J. Ethnopharmacol., 2014, vol. 154 , no. 3, pp. 481-536.

9. Shikov A.N., Makarov V.G., Ryzhenkov V.E. Rastitel'nye masla i maslianye ekstrakty: tekhnologiia, standar-tizatsiia, svoistva. [Vegetable oils and oil extracts: technology, standardization, properties]. Moscow, 2004, 264 p. (in Russ.).

10. Gosudarstvennaia Farmakopeia SSSR. [State Pharmacopoeia of the USSR]. 11 ed., Moscow, 1987, Issue 1. 335 p.; 1989, Issue 2.398 p. (in Russ.).

11. Pimenov A.I., Stankevich N.M., Makarov V.G., Zenkevich I.G. Aktual'nye problemy sozdaniia novykh lekarstvennykh preparatov prirodnogo proiskhozhdeniia: materialy $V$ mezhdun. $s^{\prime \prime} e z d a$. [Actual problems of creating new lekars $\neg$ tvennyh drugs of natural origin: Proceedings of the V International Congress]. St. Petersburg, 2001. pp. 354356. (in Russ.).

12. Kosman V.M, Zenkevich I.G. Rastitel'nye resursy, 1997, vol. 33, no. 2, pp. 14-26. (in Russ.).

13. Kosman V.M, Zenkevich I.G., Komissarenko N.F. Rastitel'nye resursy, 1997, vol. 33, no. 3, pp. 32-37. (in Russ.).

14. Shikov A.N., Laakso I., Pozharitskaya O.N., Dorman D., Makarov V.G., Tikhonov V.P., Hiltunen R. Planta Medica,. 2006, vol.72, no. 11, pp. 1026.

Received July 24, 2014

Revised October 9, 2014

\footnotetext{
* Corresponding author.
} 